\title{
Silica-coated nano calcium carbonate reinforced polychloroprene rubber nanocomposites: influence of silica coating on cure, mechanical and thermal properties
}

\author{
Kumarjyoti Roy $^{1} \cdot$ Md. Najib Alam ${ }^{1} \cdot$ Swapan Kumar Mandal ${ }^{1}$ • \\ Subhas Chandra Debnath ${ }^{1}$
}

Received: 5 June 2015/Accepted: 21 August 2015/Published online: 4 November 2015

(C) The Author(s) 2015. This article is published with open access at Springerlink.com

\begin{abstract}
The main objective of the present work is to compare the influence of silica-coated nano calcium carbonate (SNCC) with uncoated nano calcium carbonate (NCC) as filler on the property enhancement of polychloroprene rubber (CR) composites. The CR nanocomposites containing SNCC exhibit superior curing, mechanical and thermal properties in comparison to NCCfilled CR nanocomposites. The fantastic enrichment in the resulting properties of $\mathrm{CR}$ nanocomposites containing SNCC is mainly due to better rubber-filler interaction resulting from the reasonably excellent dispersion of SNCC within the $\mathrm{CR}$ matrix. The more uniform distribution of SNCC in comparison to NCC within the rubber matrix is also confirmed from morphological analysis. Thus, in this article, we report SNCC as a new type of efficient filler to reinforce the ultimate properties of $\mathrm{CR}$ nanocomposites for the first time.
\end{abstract}

Keywords Nanocomposites - Reinforcement - Cure characteristics $\cdot$ Mechanical properties $\cdot$ Thermal properties

\section{Introduction}

In recent scenario, polymer nanocomposites based on inorganic nano filler have attracted massive attention, both in industrial and academic field of research [1-5]. Unquestionably, nano filler offers advanced and versatile way to prepare innovative engineering materials with a

Subhas Chandra Debnath

debnathsubhas@yahoo.com

1 Department of Chemistry, University of Kalyani, Kalyani, Nadia 741235, India variety of application range. It is well established that, due to its large surface area and high aspect ratio, small amount of nano filler causes encouraging reinforcement in the physical properties of polymer nanocomposites [6]. However, uniform dispersion of nano filler within the rubber matrix is the key factor to achieve the desired property enhancement of rubber nanocomposites.

Now, rubber is an important polymeric material due to its high and reversible deformability [7]. Carbon nano tube, nano silica, nano clay, nano $\mathrm{CaCO}_{3}$, etc. are the some commonly used nano fillers for rubber compounds. But in the present time, nano $\mathrm{CaCO}_{3}$ has gained great attention of a modern researcher as it is the cheapest commercially available nano filler. Furthermore, nano $\mathrm{CaCO}_{3}$ has some additional advantages like low toxicity level, less polluting nature and white color [8]. Thus, nano $\mathrm{CaCO}_{3}$ is an appropriate filler for the property enhancement of rubber nanocomposites from both environmental and economic point of view. The utilization of nano $\mathrm{CaCO}_{3}$ as filler for the improvement of performance of rubber nanocomposites has been reported in the literature [8-14].

Actually, the resulting properties of rubber nanocomposites largely depend on the compatibility between nanoparticles and rubber matrix [1]. Analog calorimetric studies were utilized to explain blend miscibility of various polymer systems [15-17]. In the presence of nano filler, thermodynamic properties of rubber nanocomposites like elastic Gibbs free energy $(\Delta \mathrm{G})$ and Conformational entropy $(\Delta S)$ are very effective to study the compatibility of nano filler and rubber matrix [10, 11]. Also, elastic Gibbs free energy $(\Delta \mathrm{G})$ gives an idea about the elastic properties of rubber nanocomposites [11]. Moreover, there is a decrease in the value of elastic Gibbs free energy $(\Delta \mathrm{G})$ and increase in the value of Conformational entropy $(\Delta \mathrm{S})$ due to excellent dispersion of nano filler within rubber matrix $[10,11]$. 
Polychloroprene (CR) is commonly known as an excellent, versatile synthetic rubber with a variety of industrial application range. It has several advantages like extraordinary oil and fuel resistance, toughness, good adhesion to other materials and high heat resistance up to $100{ }^{\circ} \mathrm{C}$ [18]. The commercial application of CR was started in 1932 [19]. CR is available in both dry and latex forms. Dry grades of polychloroprene rubber are normally used in industrial and automotive rubber goods, such as hoses and belts. Latex grades of polychloroprene rubber are used in waterborne adhesives and dipped goods, such as gloves and constant velocity joint boots. Several studies have been reported on the incredible property improvement of $\mathrm{CR}$ nanocomposites in the presence of different types of nano filler [18-23]. Das et al. [18] studied the effect of surfacemodified filler on CR-based nanocomposites with two different types of clay materials, namely montmorillonite (MMT) and layered double hydroxide (LDH). It was observed that organic modification improves the reinforcing efficiency of MMT in a greater extent than that of LDH [18]. Das et al. [20] explained an approach of compatibilization between polychloroprene (CR) and ethylene propylene diene monomer rubber (EPDM) using nano clay as a compatibilizer as well as strong reinforcing filler. The remarkable improvement in the thermal stability of CR nanocomposites in the presence of ionic liquid modified multi-walled carbon nanotubes (MWCNTs) was reported by Subramaniam et al. [21]. This was mainly due to the fine dispersion of modified MWCNTs within the CR matrix [21]. Very recently, Fahma et al. [23] elucidated that excellent improvement in the mechanical properties of CR was observed due to the introduction of a small amount of cellulose nanofibers (CNFs) into the CR matrix. Moreover, most of the studies in the literature have reported fantastic property improvement of CR nanocomposites based on either MWCNTs or nano clay as nano filler. But, the vast study on nano $\mathrm{CaCO}_{3}$-filled $\mathrm{CR}$ composites is still very scanty.

In the present work, we report the effect of both uncoated and silica-coated nano $\mathrm{CaCO}_{3}$ as filler on the property enhancement of CR nanocomposites. Actually, the silanol group of silica can able to produce strong interaction with highly electronegative chlorine atom of CR [24, 25]. This interaction occurs through hydrogen bonding between the hydrogen atom of silanol group which has a locally positive charge and chlorine atom of $\mathrm{CR}$ which has a locally negative charge [25]. Thus, silica coating on the surface of nano $\mathrm{CaCO}_{3}$ will be an interesting approach to improve rubber-filler interaction of nano $\mathrm{CaCO}_{3}$-based CR composites. The purpose of this study is not just to report the property enhancement of CR composites in the presence of nano $\mathrm{CaCO}_{3}$, but also to determine the efficiency of silica coating in improving the dispersion of nano $\mathrm{CaCO}_{3}$ within the $\mathrm{CR}$ matrix and promoting the vulcanizate properties of $\mathrm{CR}$ nanocomposites.

\section{Experimental}

\section{Materials and physical measurements}

Polychloroprene rubber used in this study is of WRT grade with Mooney viscosity $45 \mathrm{ml}$ at $100{ }^{\circ} \mathrm{C}, 1+4 \mathrm{~min}$. Zinc oxide $(\mathrm{ZnO})$ (Merck, Germany), magnesium oxide $(\mathrm{MgO})$ (Merck, Germany), stearic acid (Loba Chemie, India), calcium chloride (Merck, Germany), poly(ethylene glycol) (PEG; molecular weight 6000), potassium bicarbonate (Merck, Germany), toluene (Merck, Germany) and ammonia $25 \%$ (Merck, Germany) are used as received. Tetraethyl orthosilicate (TEOS) is purchased from Acros Organics. Absolute ethanol is supplied by Bengal Chemicals and Pharmaceuticals, India. Ethylene thiourea (ETU) is provided by a local supplier. The synthesis of nano $\mathrm{CaCO}_{3}$ is done using the procedure given by Mishra et al. [9].

Fourier transform infrared (FTIR) spectra $\left(v_{\max }\right.$ in $\left.\mathrm{cm}^{-1}\right)$ of surface-coated nano $\mathrm{CaCO}_{3}$ are recorded on a PerkinElmer L 120-000A spectrometer $\left(v_{\max }\right.$ in $\left.\mathrm{cm}^{-1}\right)$ on $\mathrm{KBr}$ disks. Field emission scanning electron microscopy (FESEM) study is carried out on instrument JSM 6700F. The cure characteristics of the different samples are performed at $160{ }^{\circ} \mathrm{C}$ using the Monsanto Rheometer R-100. The vulcanizates are cured under pressure at $160{ }^{\circ} \mathrm{C}$ for optimum cure time $\left(t_{90}\right)$ and placed for $24 \mathrm{~h}$ at room temperature before measuring the mechanical properties like modulus at $100 \%$ $\left(M_{100}\right)$ elongation, modulus at $300 \%\left(M_{300}\right)$ elongation, tensile strength (T.S.), elongation at break (E.B. in \%) according to ASTM D 412-51 T using dumbbell-shaped test pieces in an Amsler (Sweden) tensile tester. Hardness (shore A) of the vulcanizates is measured by a Hirosima Hardness Tester as per ASTM D 1415-56T. Thermogravimetric analysis (TGA) is carried out to study the thermal behavior of CR vulcanizates. TGA scans are performed using a TA instrument (Q 5000) under nitrogen flow from 20 to $700{ }^{\circ} \mathrm{C}$ with a heating rate of $10{ }^{\circ} \mathrm{C} / \mathrm{min}$. To determine the rubberfiller interaction of CR vulcanizates, the small sample pieces are allowed to swell in toluene for 7 days. The sample pieces are dried at $60{ }^{\circ} \mathrm{C}$ until a constant weight is achieved. Then, the equation of Lorentz and Park [26] is utilized to determine the rubber-filler interaction of $\mathrm{CR}$ nanocomposites. The Lorentz-Park equation [26] is given as:

$Q_{f} / Q_{g}=a e^{-z}+b$

where the subscripts $f$ and $g$ refer to the filled and gum CR vulcanizates, respectively, $z$ is the ratio of the weight of the filler to the rubber hydrocarbon in the vulcanizates, and 
$a$ and $b$ are constants. The weight of toluene uptake per gram of rubber hydrocarbon (Q) is determined by the following equation [26]:

$Q=\left(W_{\mathrm{s}}-W_{\mathrm{d}}\right) /\left(W_{\mathrm{i}} \times 100 /\right.$ Formula weight $)$

where $W_{\mathrm{s}}$ is the swollen weight, $W_{\mathrm{d}}$ is the dried weight, and $W_{\mathrm{i}}$ is the original weight.

\section{Surface coating of synthesized $\mathrm{CaCO}_{3}$ nanoparticles}

Surface coating of nano $\mathrm{CaCO}_{3}$ is done via sol-gel method. In the first step, a solution is prepared by mixing $13.5 \mathrm{ml}$ water, $126.5 \mathrm{ml}$ ethanol and $3.37 \mathrm{ml} 25 \% \mathrm{NH}_{3}$ in a $250 \mathrm{ml}$ beaker. Then, $1.5 \mathrm{~g}$ nano $\mathrm{CaCO}_{3}$ and $6.75 \mathrm{ml}$ TEOS are added to the initially prepared solution under continuous mechanical stirring. The resulting mixture is then kept at room temperature for $24 \mathrm{~h}$ under constant stirring. The resulting product is then filtered and washed with ethanol. Finally, it is dried in a vacuum oven for 5-6 days. A very similar type of procedure was reported earlier by Gamelas et al. [27] in the surface coating of precipitated calcium carbonate with sol-gel derived silica.

The mechanism of silica formation from TEOS is explained in Scheme 1 [28]. In the first step, the hydrolysis of TEOS occurs in the presence of water and $\mathrm{NH}_{3}$ to produce $\mathrm{Si}(\mathrm{OH})_{4}$. The role of $\mathrm{NH}_{3}$ solution is to promote the hydrolysis of TEOS. In the next step, monomers or oligomers of polysiloxane are formed by the reaction of $\mathrm{Si}(\mathrm{OH})_{4}$ with other $\mathrm{Si}(\mathrm{OH})_{4}$ or TEOS molecule. Subsequently, oligomers of polysiloxane polymerize to form polysiloxane with a three-dimensional network structure. Ethanol is used to homogenize the mixture of water and
TEOS. Due to its very high activity, the oligomers of polysiloxane along with $\mathrm{Si}(\mathrm{OH})_{4}$ readily adsorb to the surface of nano $\mathrm{CaCO}_{3}$. Then, silica polymerizes on the surface of nano $\mathrm{CaCO}_{3}$ and, as a consequence, the surface of the nano $\mathrm{CaCO}_{3}$ is readily covered by silica film.

\section{Preparation of CR nanocomposites}

$\mathrm{CR}$ is masticated in a two-roll mixing mill, and then the requisite amount of $\mathrm{MgO}$ is added and again masticated. After that uncoated and silica-coated nano $\mathrm{CaCO}_{3}$ are added and masticated for sufficient time. Then, stearic acid and accelerator are incorporated into the rubber matrix. At last, $\mathrm{ZnO}$ is added after cooling down the mixing mill at $30{ }^{\circ} \mathrm{C}$. Mixing composition of different ingredients is presented in Table 1. For the different mixes, CR indicates polychloroprene rubber, number indicates the amount of filler in phr (Parts per hundred parts of rubber), NCC indicates uncoated nano $\mathrm{CaCO}_{3}$ particle, SNCC indicates silica-coated nano $\mathrm{CaCO}_{3}$ particle, as for example mix CRNCC1 represents $\mathrm{CR}$ vulcanizate containing $1 \mathrm{phr}$ nano $\mathrm{CaCO}_{3}$. Similarly, mix CR-SNCC1 represents CR vulcanizate containing $1 \mathrm{phr}$ silica-coated nano $\mathrm{CaCO}_{3}$.

\section{Results and discussion}

\section{Confirmation of surface coating of $\mathrm{CaCO}_{3}$ nanoparticle}

FTIR method is utilized to examine whether the silica coating on the surface of nano $\mathrm{CaCO}_{3}$ occurs or not. The
Scheme 1 Chemistry of silica formation by sol-gel process

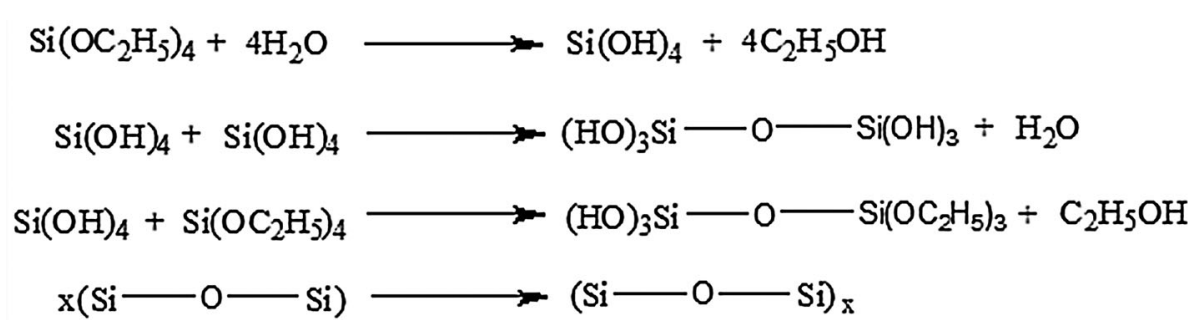

Table 1 The formulation of polychloroprene rubber $(\mathrm{CR})$ nanocomposites

\begin{tabular}{llll}
\hline Sample code & Polychloroprene rubber $(\mathrm{CR})$ & Uncoated nano $\mathrm{CaCO}_{3}$ & Silica-coated nano $\mathrm{CaCO}_{3}$ \\
\hline CR-Gum & 100 & - & - \\
$\mathrm{CR}-\mathrm{NCC} 1$ & 100 & 1 & - \\
$\mathrm{CR}-\mathrm{NCC} 2$ & 100 & 2 & - \\
$\mathrm{CR}-\mathrm{NCC} 3$ & 100 & 3 & - \\
CR-SNCC1 & 100 & - & 1 \\
CR-SNCC2 & 100 & - & 2 \\
CR-SNCC3 & 100 & - & 3 \\
\hline
\end{tabular}

Each sample contains $4 \mathrm{~g} \mathrm{MgO}, 5 \mathrm{~g} \mathrm{ZnO}, 0.5 \mathrm{~g}$ stearic acid and $1 \mathrm{~g}$ ethylene thiourea 
Fig. 1 FTIR spectra of silicacoated nano $\mathrm{CaCO}_{3}$

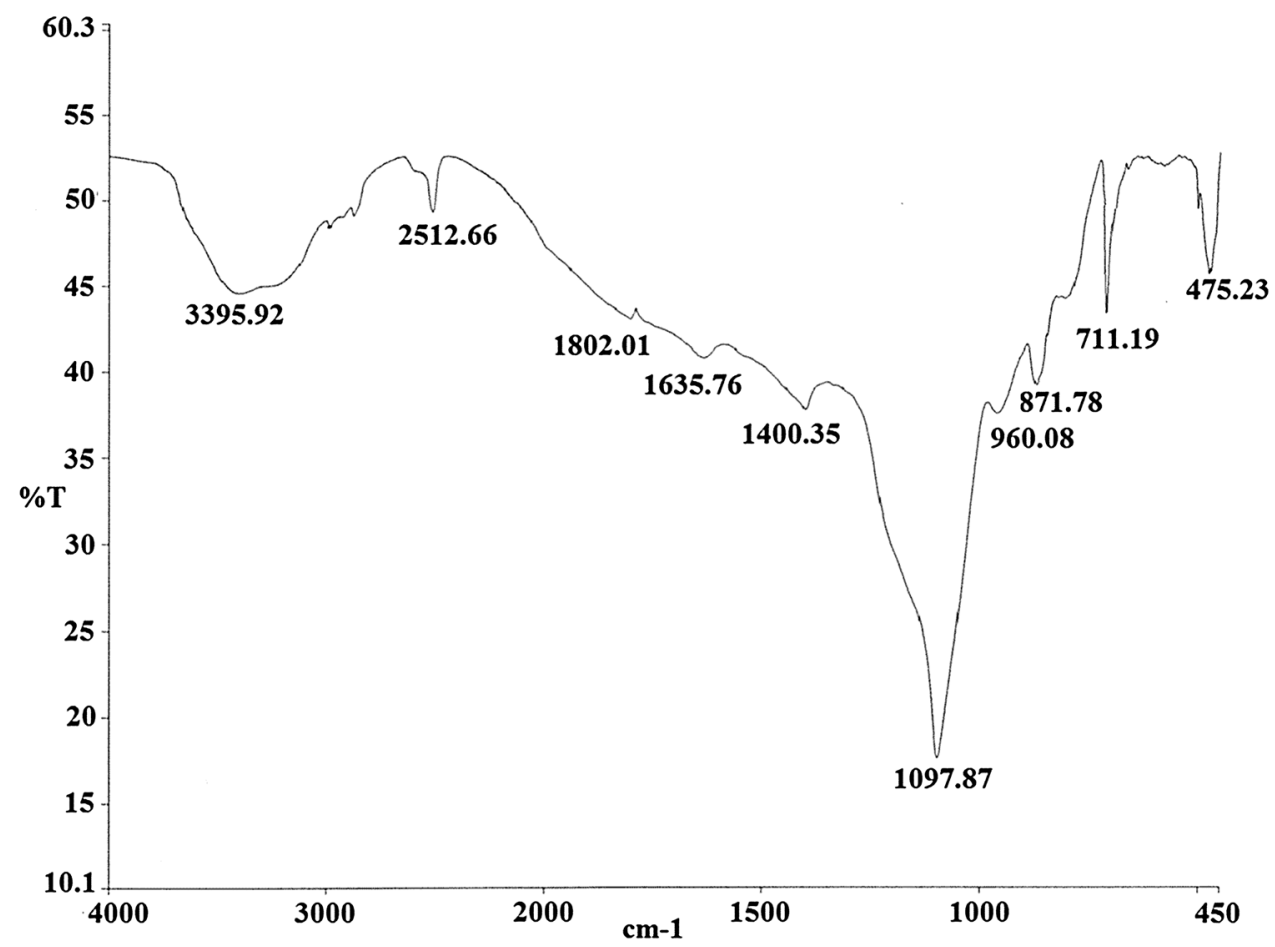

FTIR spectra of the silica-coated nano $\mathrm{CaCO}_{3}$ are represented in Fig. 1. In the FTIR spectra of silica-coated nano $\mathrm{CaCO}_{3}$, some characteristic bands of $\mathrm{CaCO}_{3}$ are found at about 872 and $712 \mathrm{~cm}^{-1}$ [27]. More importantly, a strong peak is observed at about $1100 \mathrm{~cm}^{-1}$ in the FTIR spectra of silica-coated nano $\mathrm{CaCO}_{3}$. This peak is due to the $\mathrm{Si}-\mathrm{O}-\mathrm{Si}$ asymmetric stretching of silica present at nano $\mathrm{CaCO}_{3}$ surface [29]. This peak clearly tells that silica is produced on the surface of $\mathrm{CaCO}_{3}$ nanoparticle via sol-gel method.

The presence of silica on the surface of $\mathrm{CaCO}_{3}$ nanoparticle is confirmed by FESEM analysis. The FESEM images of both uncoated and silica-coated nano $\mathrm{CaCO}_{3}$ are represented in Fig. 2a, b. The particle size of uncoated nano $\mathrm{CaCO}_{3}$ varies from 50 to $90 \mathrm{~nm}$. The particle size slightly increases due to the formation of silica layer on the surface of nano $\mathrm{CaCO}_{3}$ and particle size is $\sim 10 \mathrm{~nm}$ larger for SNCC in comparison to NCC.

\section{Cure characteristics of CR nanocomposites}

Cure parameters of $\mathrm{CR}$ vulcanizates in the presence of both NCC and SNCC are calculated at $160{ }^{\circ} \mathrm{C}$ and the results are displayed in Table 2 . The cure characteristics of CR vulcanizates are elucidated in terms of maximum rheometric torque $\left(R_{\infty}\right)$, optimum cure time $\left(t_{90}\right)$ and cure rate index $(\mathrm{CRI})$.

The value of maximum rheometric torque $\left(R_{\infty}\right)$ is closely related to the crosslinking degree of rubber vulcanizates [30]. For CR nanocomposites, the value of $R_{\infty}$ slightly increases with incorporation of NCC as filler in comparison to unfilled $\mathrm{CR}$ vulcanizate. The $R_{\infty}$ value shows a small increment by $\sim 9 \%$ for CR nanocomposite containing 2 phr NCC in comparison to unfilled CR composite. The little enhancement in the $R_{\infty}$ value may be due to the interaction between NCC and polar CR matrix in nano $\mathrm{CaCO}_{3}$-filled $\mathrm{CR}$ vulcanizates [31]. Again, the study clearly indicates that the interfacial interaction between $\mathrm{CR}$ and filler becomes far better when SNCC is introduced as filler instead of NCC. As a result, $R_{\infty}$ value shows a noticeable increment by $\sim 19.32 \%$ for CR-SNCC2 containing 2 phr SNCC in comparison to CR-Gum. However, due to the agglomeration of $\mathrm{CaCO}_{3}$ nanoparticles, both NCC and SNCC are not effective to increase the value of $R_{\infty}$ above 2 phr level [9, 31].

The value of optimum cure time $\left(t_{90}\right)$ decreases on addition of both NCC and SNCC into the CR matrix. Thus, both the fillers are able to activate the cure reaction during vulcanization of CR. The variation of cure rate index (CRI) with an amount of filler content is illustrated in Fig. 3. The value of CRI indicates that at the same amount of filler loading, the cure process becomes much faster in the presence of SNCC as filler instead of NCC. Thus, SNCC has undoubtedly much greater ability in accelerating the vulcanization process of CR nanocomposites in comparison to NCC.

\section{Mechanical properties of CR nanocomposites}

The mechanical properties of $\mathrm{CR}$ nanocomposites in the presence of both NCC and SNCC are listed in Table 2. 

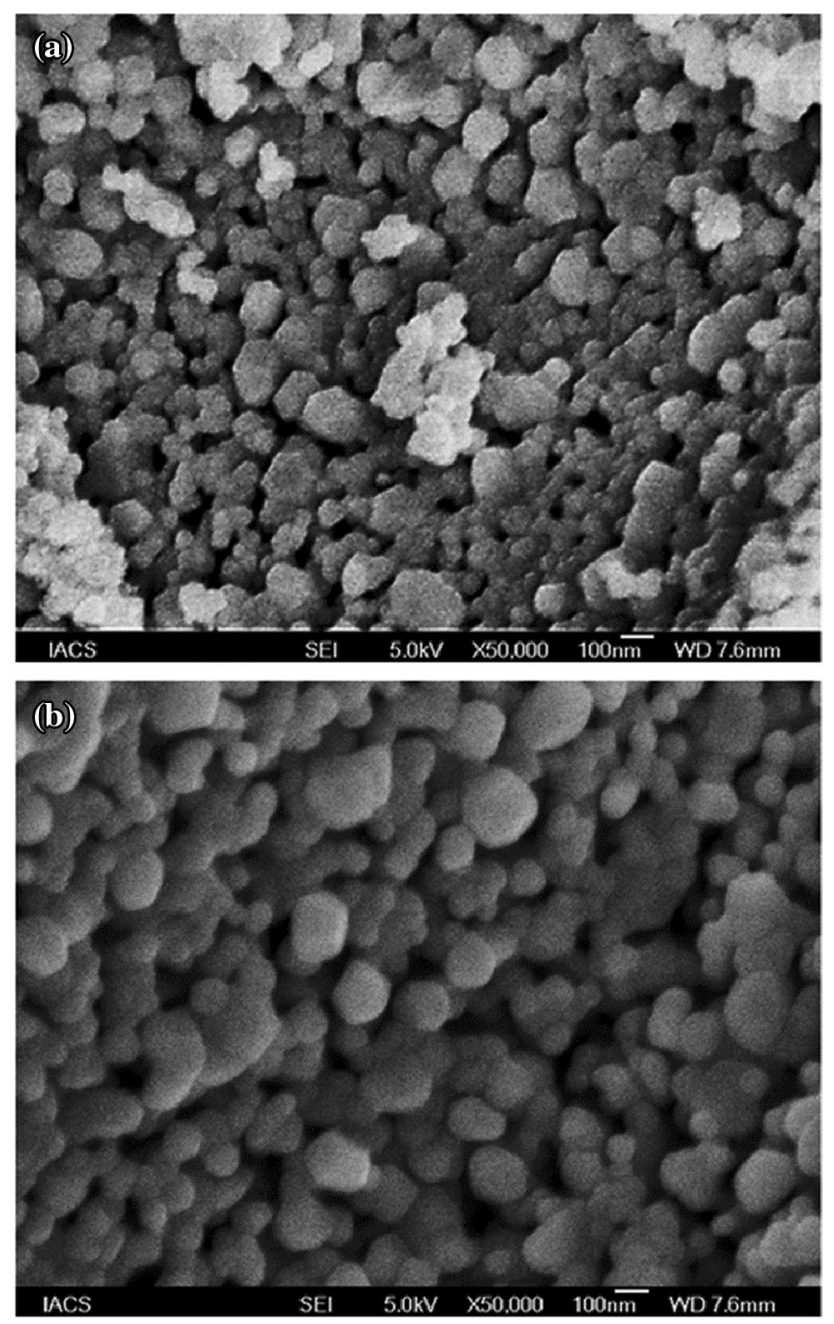

Fig. 2 SEM images of a uncoated and $\mathbf{b}$ silica-coated nano $\mathrm{CaCO}_{3}$

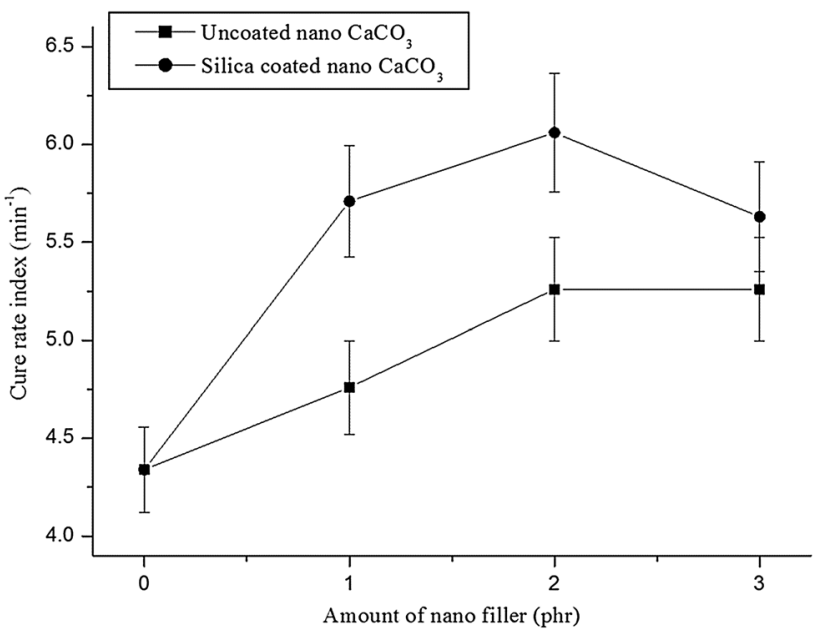

Fig. 3 Variation of cure rate index of CR nanocomposites

There is an increase in the modulus value due to incorporation of both types of filler into the CR matrix in comparison to unfilled $\mathrm{CR}$ vulcanizate. But the improvement is much more noticeable in the presence of SNCC. The ratio of modulus value at $100 \%$ elongation of filled vulcanizate ( $\left.M_{100 f}\right)$ to that value of gum vulcanizate $\left(M_{100 \mathrm{~g}}\right)$ is utilized to compare reinforcing efficiency of SNCC with NCC. Figure 4 displays the ratio $\left(M_{100 \mathrm{f}} / M_{100 \mathrm{~g}}\right)$ of both NCC- and SNCC-filled CR composites with different amount of filler loading. These data clearly indicate that at the same amount of filler loading, SNCC causes greater amount of improvement in the $M_{100}$ value in comparison to NCC. As a consequence, the interfacial interaction between $\mathrm{CR}$ and nano $\mathrm{CaCO}_{3}$ becomes much better after surface coating of

Table 2 Cure and mechanical properties of $\mathrm{CR}$ composites in the presence of uncoated and silica-coated nano $\mathrm{CaCO}_{3}$

\begin{tabular}{|c|c|c|c|c|c|c|c|c|c|}
\hline $\begin{array}{l}\text { Sample } \\
\text { code }\end{array}$ & $\begin{array}{l}\text { Maximum } \\
\text { rheometric } \\
\text { torque, } R_{\infty} \\
(\mathrm{dNm})\end{array}$ & $\begin{array}{l}\text { Optimum } \\
\text { cure time, } \\
t_{90}(\mathrm{~min})\end{array}$ & $\begin{array}{l}\text { Scorch } \\
\text { time, } t_{2} \\
(\min )\end{array}$ & $\begin{array}{l}\text { Cure rate index, } \\
\text { CRI }=100 / \\
\left(t_{90}-t_{2}\right) \\
\left(\min ^{-1}\right)\end{array}$ & $M_{100}(\mathrm{MPa})$ & $M_{300}(\mathrm{MPa})$ & T.S. (MPa) & E.B. $(\%)$ & $\begin{array}{l}\text { Hardness } \\
\text { (shore A) }\end{array}$ \\
\hline CR-Gum & $44 \pm 0.50$ & $24 \pm 0.25$ & $1 \pm 0.25$ & 4.34 & $1.46 \pm 0.01$ & $2.88 \pm 0.01$ & $8.46 \pm 0.10$ & $540 \pm 10$ & $62 \pm 0.5$ \\
\hline $\begin{array}{l}\text { CR- } \\
\text { NCC1 }\end{array}$ & $46.5 \pm 0.50$ & $22 \pm 0.25$ & $1 \pm 0.25$ & 4.76 & $1.62 \pm 0.01$ & $3.12 \pm 0.01$ & $8.89 \pm 0.10$ & $520 \pm 10$ & $63 \pm 0.5$ \\
\hline $\begin{array}{l}\text { CR- } \\
\text { NCC2 }\end{array}$ & $48 \pm 0.50$ & $20 \pm 0.25$ & $1 \pm 0.25$ & 5.26 & $1.79 \pm 0.01$ & $3.44 \pm 0.01$ & $10.04 \pm 0.10$ & $510 \pm 10$ & $63 \pm 0.5$ \\
\hline $\begin{array}{l}\text { CR- } \\
\text { NCC3 }\end{array}$ & $47 \pm 0.50$ & $20 \pm 0.25$ & $1 \pm 0.25$ & 5.26 & $1.69 \pm 0.01$ & $3.39 \pm 0.01$ & $9.25 \pm 0.10$ & $510 \pm 10$ & $63.5 \pm 0.5$ \\
\hline $\begin{array}{l}\text { CR- } \\
\text { SNCC1 }\end{array}$ & $50 \pm 0.50$ & $19 \pm 0.25$ & $1.5 \pm 0.25$ & 5.71 & $1.83 \pm 0.01$ & $3.53 \pm 0.01$ & $10.72 \pm 0.10$ & $550 \pm 10$ & $65 \pm 0.5$ \\
\hline $\begin{array}{l}\text { CR- } \\
\text { SNCC2 }\end{array}$ & $52.5 \pm 0.50$ & $18 \pm 0.25$ & $1.5 \pm 0.25$ & 6.06 & $1.96 \pm 0.01$ & $3.70 \pm 0.01$ & $11.93 \pm 0.10$ & $560 \pm 10$ & $65 \pm 0.5$ \\
\hline $\begin{array}{l}\text { CR- } \\
\text { SNCC3 }\end{array}$ & $52 \pm 0.50$ & $19 \pm 0.25$ & $1.25 \pm 0.25$ & 5.63 & $1.85 \pm 0.01$ & $3.64 \pm 0.01$ & $11.35 \pm 0.10$ & $560 \pm 10$ & $65 \pm 0.5$ \\
\hline
\end{tabular}




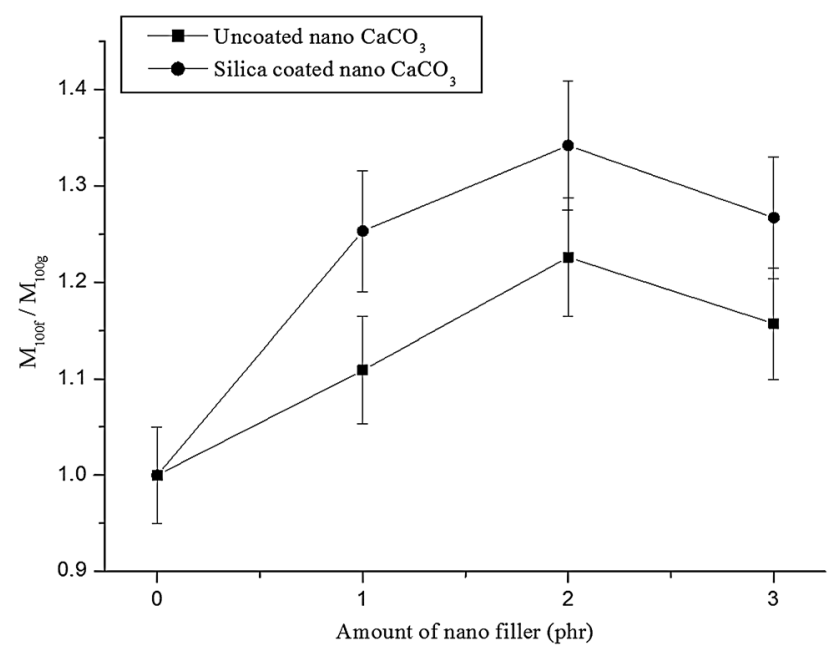

Fig. 4 Variation of ratio $\left(M_{100 f} / M_{100 \mathrm{~g}}\right)$ of $\mathrm{CR}$ nanocomposites

nano $\mathrm{CaCO}_{3}$ with silica. This may be due to the hydrogen bonding between silica present at the surface of nano $\mathrm{CaCO}_{3}$ and electronegative chlorine atom present at the end of rubber chain. This agreement is found to be similar to the improvement of maximum rheometric torque as discussed earlier part of the paper.

The notified reinforcing ability of SNCC is further established from the tensile strength curve of $\mathrm{CR}$ nanocomposites presented in Fig. 5. The strong interaction between the silanol group around the nano $\mathrm{CaCO}_{3}$ surface and a chlorine atom of $\mathrm{CR}$ is responsible for the uniform dispersion of SNCC within the CR matrix in comparison to NCC. Therefore, at the same amount of filler loading SNCC has much better ability to increase tensile strength in comparison to NCC. The tensile strength is observed to improve by $41.01 \%$ for CR-SNCC 2 and by $18.67 \%$ for CR-NCC2 in comparison to CR-Gum. The homogeneous distribution SNCC is also confirmed in the FESEM images latter. The value of elongation at break remains almost unaltered for different $\mathrm{CR}$ nanocomposites. Above $2 \mathrm{phr}$ filler loading, nano $\mathrm{CaCO}_{3}$ has the tendency to agglomerate and the reinforcing ability is not satisfactory for both types of filler [9, 31].

A probable model for strong hydrogen bonding interaction between acidic silanol group present at nano $\mathrm{CaCO}_{3}$ surface and chlorine atom in CR is shown in Scheme 2. The interaction between silanol group and CR was already represented by earlier researcher [24, 25]. The silica can able to form linkage at the interface of nano $\mathrm{CaCO}_{3}$ and $\mathrm{CR}$ matrix. Thus, silica present at the surface of nano $\mathrm{CaCO}_{3}$ can able to enhance the compatibility between $\mathrm{CR}$ matrix and nano $\mathrm{CaCO}_{3}$. Very similar type of interaction between silica coated on the surface of $\mathrm{CaCO}_{3}$ and the hydroxyl group of poly (lactic acid) matrix was already reported by earlier researcher [28].

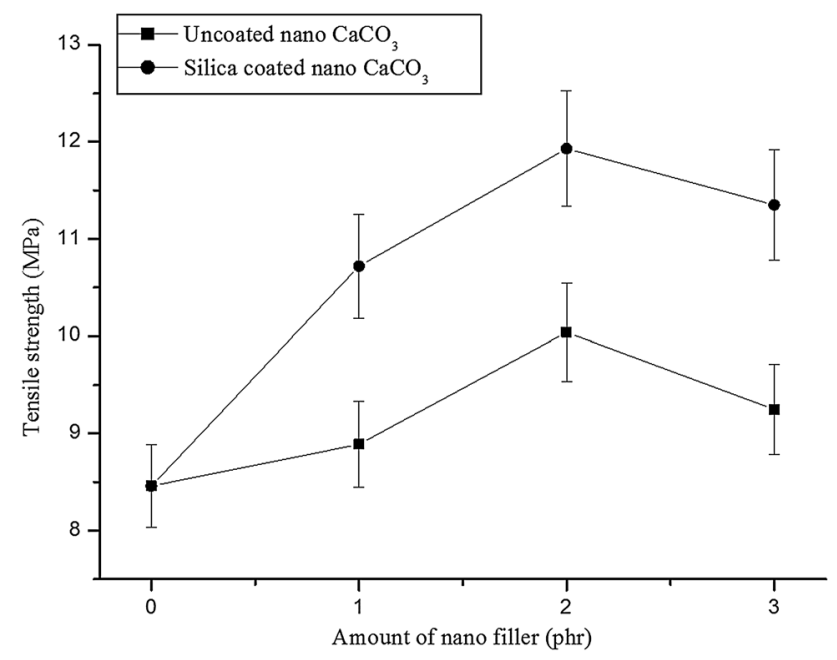

Fig. 5 Variation of tensile strength of CR nanocomposites

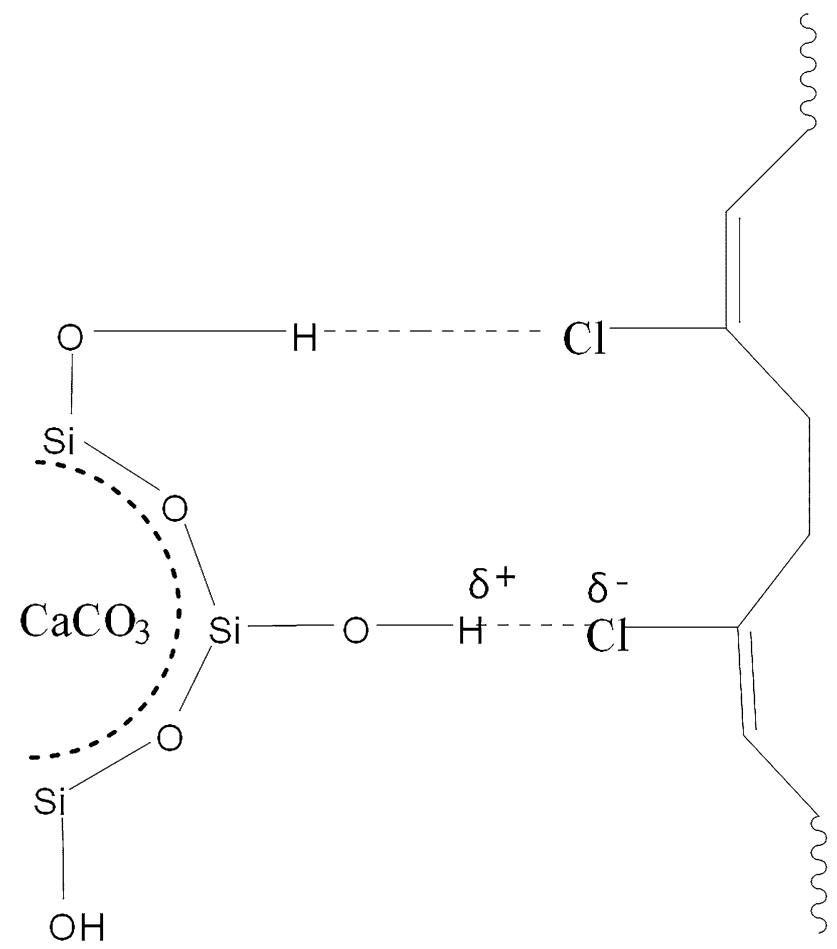

Scheme 2 Model of interaction between the silanol group present at nano $\mathrm{CaCO}_{3}$ surface and $\mathrm{CR}$

\section{Rubber-filler interaction of CR nanocomposites}

The extent of rubber-filler interaction for different CR nanocomposites is explained in terms of Lorentz-Park equation [26]. The higher the value of $\left(Q_{\mathrm{f}} / Q_{\mathrm{g}}\right)$, the lower will be the extent of interaction between filler and rubber matrix [26]. Figure 6 demonstrates the $\left(Q_{\mathrm{f}} / Q_{\mathrm{g}}\right)$ value of both NCC- and SNCC-filled CR nanocomposites in the presence of different amount of filler loading. It is 


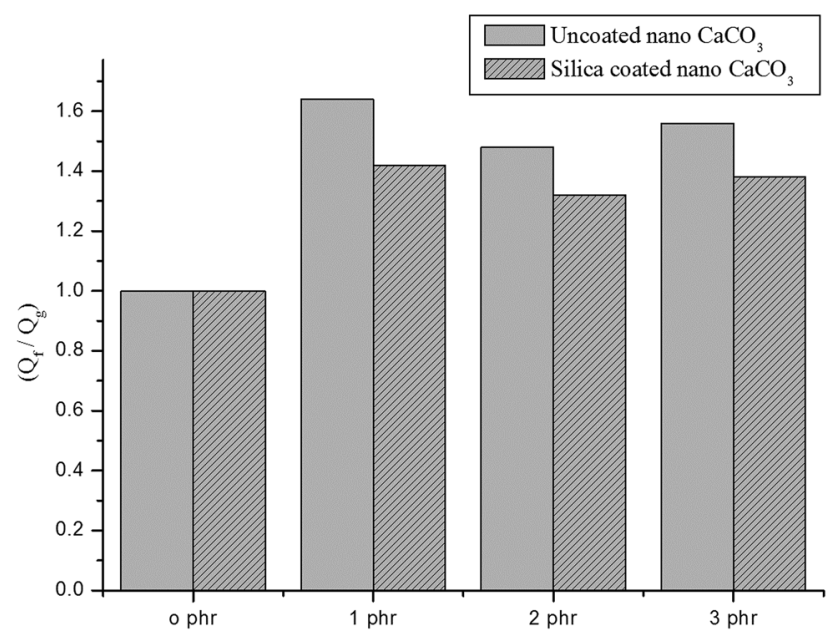

Fig. 6 Variation of $\left(Q_{\mathrm{f}} / Q_{\mathrm{g}}\right)$ for various CR nanocomposites

perceptibly observed that for a particular amount of filler loading, the value of $\left(Q_{\mathrm{f}} / Q_{\mathrm{g}}\right)$ is greater for SNCC-filled CR nanocomposite in comparison to NCC-filled $\mathrm{CR}$ nanocomposite. Among the various filled $\mathrm{CR}$ nanocomposites, the value of $\left(Q_{\mathrm{f}} / Q_{\mathrm{g}}\right)$ is lowest in the presence of 2 $\mathrm{phr}$ SNCC. The result conclusively indicates that SNCC is capable of producing greater rubber-filler interaction in comparison to NCC. This is due to the more homogeneous dispersion of SNCC than that of NCC within the CR matrix as confirmed by morphological study in the next part of the paper.

\section{Morphology of CR nanocomposites}

The phase morphology of CR vulcanizates containing both NCC and SNCC is studied to evaluate the nature of dispersion of nano filler within the rubber matrix. At $2 \mathrm{phr}$ filler level, the FESEM images of CR vulcanizate containing both NCC and SNCC are shown in Fig. 7. The black phase indicates $\mathrm{CR}$ matrix and white dot represents agglomerated nano $\mathrm{CaCO}_{3}$ particles. Figure 7a clearly indicates large amount of agglomeration present within the $\mathrm{CR}$ matrix in the presence of NCC as filler. On the other hand, Fig. 7b specifies that SNCC is much more homogeneously dispersed in comparison to NCC within the rubber matrix and very small amount of agglomeration is detected. This fact clearly explains the greater reinforcing ability of SNCC to enhance the rubber-filler interaction and mechanical properties of $\mathrm{CR}$ vulcanizates in comparison to NCC.

\section{Thermodynamic parameters of CR nanocomposites}

Table 3 represents the variation of thermodynamic parameters like elastic Gibbs free energy $(\Delta G)$ and
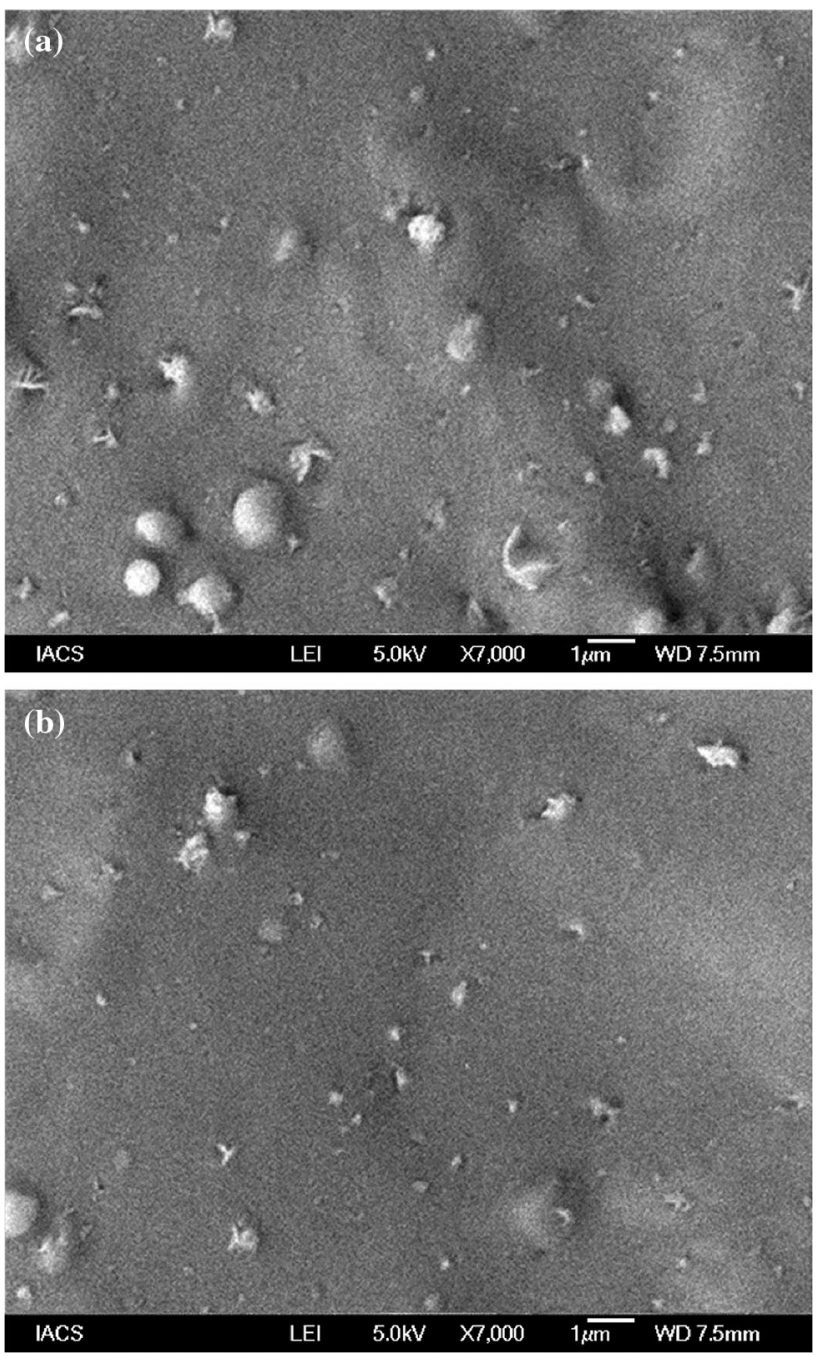

Fig. 7 a SEM image of uncoated nano $\mathrm{CaCO}_{3}$-filled $\mathrm{CR}$ composite, b SEM image of silica-coated nano $\mathrm{CaCO}_{3}$-filled $\mathrm{CR}$ composite

Table 3 Thermodynamic parameters of CR composites in the presence of uncoated and silica-coated nano $\mathrm{CaCO}_{3}$

\begin{tabular}{lll}
\hline Sample code & $\Delta \mathrm{G}(\mathrm{J} / \mathrm{mol})$ & $\Delta \mathrm{S} \times 10^{-2}(\mathrm{~J} / \mathrm{mol})$ \\
\hline CR-Gum & -15.59 & 5.14 \\
CR-NCC2 & -16.68 & 5.50 \\
CR-SNCC2 & -18.04 & 5.95 \\
\hline
\end{tabular}

conformational entropy $(\Delta \mathrm{S})$ of various rubber nanocomposites. Flory-Huggins equation [32] is utilized to calculate the elastic Gibbs free energy $(\Delta \mathrm{G})$ of rubber vulcanizates. Flory-Huggins equation [32] is written as:

$\Delta G=R T\left[\ln \left(1-V_{\mathrm{r}}\right)+V_{\mathrm{r}}+\chi V_{\mathrm{r}}^{2}\right]$

where $R$ is the universal gas constant, $T$ is the absolute temperature, $V_{\mathrm{r}}$ is the volume fraction of a rubber network 
Fig. 8 a TGA analysis of CR nanocomposites, b DTA analysis of CR nanocomposites

in the swollen phase, and $\chi$ is the rubber-solvent interaction parameter.

The value of $V_{\mathrm{r}}$ is determined from equilibrium swelling data with the help of Flory-Rehner equation [33],

$V_{r}=\left(W_{2} / d_{2}\right) /\left\{\left(W_{1} / d_{1}\right)+\left(W_{2} / d_{2}\right)\right\}$

where $W_{1}$ represents a weight fraction of the solvent, $d_{1}$ is the density of the solvent, $W_{2}$ represents a weight fraction of the polymer in the swollen specimen and $d_{2}$ is the density of the polymer. For the chloroprene rubber-toluene system, $\chi=0.386$ [34], the molar volume of toluene $V_{\mathrm{s}}$ is $106.2 \mathrm{~cm}^{3} / \mathrm{mol}$, and the density of toluene is $0.87 \mathrm{~g} / \mathrm{cm}^{3}$.

The relation between $\Delta \mathrm{G}$ and $\Delta \mathrm{S}$ is obtained from statistical theory of rubber elasticity and it is given by the following equation, $\Delta \mathrm{G}=-\mathrm{T} \Delta \mathrm{S}$, which assumes that the internal energy of rubber network remains unchanged during stretching $[35,36]$. It is clearly noted from Table 3 that Conformational entropy $(\Delta \mathrm{S})$ of $\mathrm{CR}-\mathrm{SNCC} 2$ is higher (a)

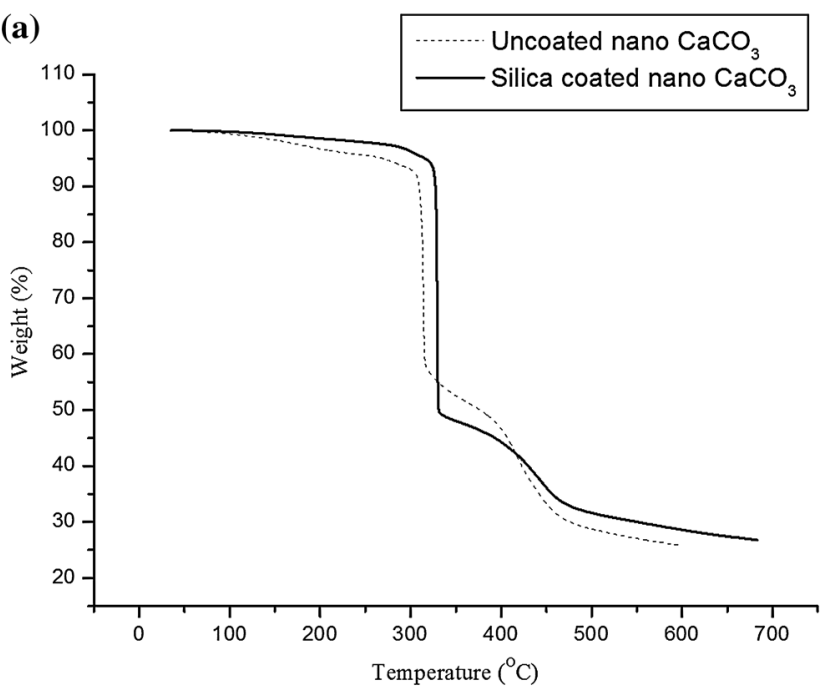

(b)
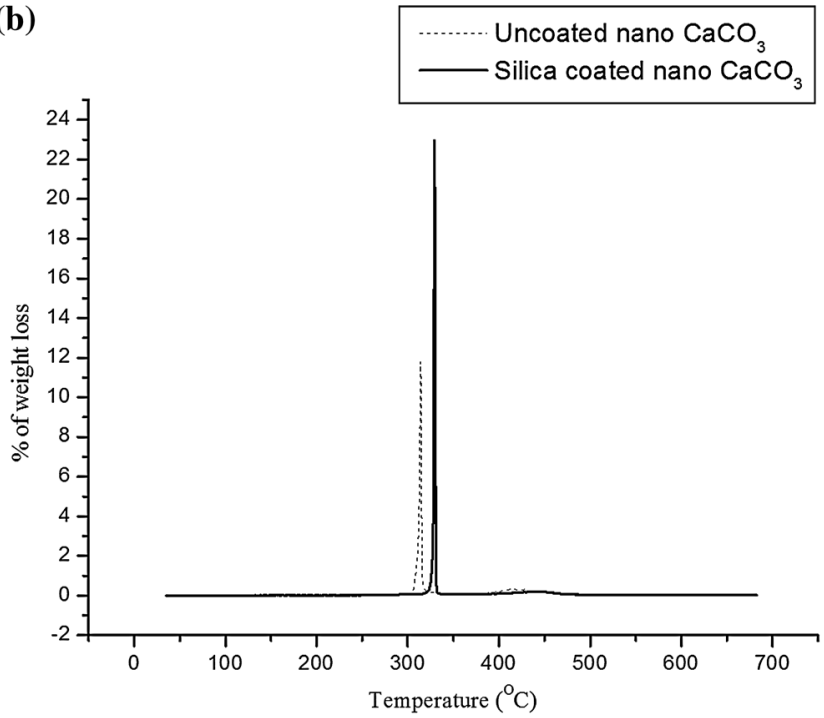

in comparison to CR-NCC2. The uniform dispersion of SNCC within the rubber matrix is the main factor for the higher value of $\Delta \mathrm{S}$ in CR-SNCC2 [35, 36]. Again, for rubber nanocomposites, the value of $\Delta \mathrm{G}$ is closely related to the elastic properties of the composites [35, 36]. Thus, the value of $\Delta G$ clearly evidences the greater elastic behavior of CR-SNCC2 in comparison to CR-NCC2. The improved elastic performance of CR-SNCC2 containing SNCC as filler is the result of better compatibility between CR matrix and SNCC $[35,36]$.

\section{Thermal properties of CR nanocomposites}

Thermogravimetric analysis (TGA) is used to compare the thermal stability of CR-SNCC2 with CR-NCC2. TGA curve (Fig. 8a) reveals that there is a sharp shift of rapid degradation region towards higher temperature after 
addition of SNCC into the rubber matrix in comparison to NCC. Furthermore, DTA curve (Fig. 8b) confirms that SNCC provides greater thermal stability as compared to NCC for CR nanocomposites at the same amount of filler loading. The onset decomposition temperature $\left(T_{\mathrm{i}}\right)$ and the temperature at which the rate of decomposition is maximum $\left(T_{\max }\right)$ are calculated from DTA curves. The $T_{\mathrm{i}}$ values are recorded at 320 and $304{ }^{\circ} \mathrm{C}$ for CR-SNCC2 and CRNCC2, respectively. The $T_{\max }$ value of CR-SNCC2 is also $\sim 15{ }^{\circ} \mathrm{C}$ greater for CR-SNCC2 than that of CR-NCC2. Thus, DTA study obviously specifies that SNCC-based CR nanocomposite has remarkably greater thermal stability over CR nanocomposite with NCC. The uniform dispersion of SNCC within the rubber matrix restricts thermal motion of rubber chain within the network structure and prevents the diffusion of volatile decomposition products [11]. Also, uniform dispersion of SNCC causes homogeneous heat distribution throughout the rubber matrix to avoid heat concentration [12]. Both the reasons are responsible for the enhanced thermal stability of CR nanocomposite due to the incorporation of SNCC into the rubber matrix in comparison to NCC.

\section{Conclusions}

In summary, the present paper mainly demonstrates the suitability of silica-coated nano $\mathrm{CaCO}_{3}$ (SNCC) over uncoated nano $\mathrm{CaCO}_{3}$ (NCC) as filler for $\mathrm{CR}$ nanocomposites. The CR nanocomposites containing SNCC exhibit better curing, mechanical and thermal properties in comparison to unfilled or NCC-filled CR nanocomposites. SNCC also introduces greater rubber-filler interaction in the CR nanocomposites in comparison to NCC. The significant reinforcement in the achieved properties $\mathrm{CR}$ nanocomposites in combination with SNCC is probably due to the uniform dispersion of silica-coated filler within the rubber matrix resulting from the strong interaction of silanol group present at the surface of SNCC and electronegative chlorine atom of $\mathrm{CR}$.

From this study, it is concluded that silanol group present at the surface of SNCC can able to provide stronger interaction between $\mathrm{CR}$ and SNCC than that of $\mathrm{CR}$ and NCC. Thus, SNCC is much more effective filler in comparison to NCC for the property improvement of CR. Therefore, the present work highlights the important impact on the development of rubber technology by the suitable use of SNCC as a new type of filler in CR-based nanocomposites.

Acknowledgments The authors thankfully acknowledge the Department of Science and Technology, West Bengal for financial support. The authors also thank DST-FIST Programme, Govt. of India and UGC-SAP DRS-II Programme, Govt. of India for instrumental support. Mr. Kumarjyoti Roy sincerely thanks University of Kalyani for fellowship assistance.

Open Access This article is distributed under the terms of the Creative Commons Attribution 4.0 International License (http://crea tivecommons.org/licenses/by/4.0/), which permits unrestricted use, distribution, and reproduction in any medium, provided you give appropriate credit to the original author(s) and the source, provide a link to the Creative Commons license, and indicate if changes were made.

\section{References}

1. Roy, K., Alam, M.N., Mandal, S.K., Debnath, S.C.: Surface modification of sol-gel derived nano zinc oxide $(\mathrm{ZnO})$ and the study of its effect on the properties of styrene-butadiene rubber (SBR) nanocomposites. J. Nanostruct. Chem. 4, 133-142 (2014)

2. Jahanmardi, R., Kangarlou, B., Dibazar, A.R.: Effects of organically modified nanoclay on cellular morphology, tensile properties, and dimensional stability of flexible polyurethane foams. J. Nanostruct. Chem. 3, 82 (2013)

3. Shokrieh, M.M., Saeedi, A., Chitsazzadeh, M.: Mechanical properties of multi-walled carbon nanotube/polyester nanocomposites. J. Nanostruct. Chem. 3, 20 (2013)

4. Azizli, M.J., Naderi, G., Bakhshandeh, G.R., Soltani, S., Askari, F., Esmizadeh, E.: Improvement in physical and mechanical properties of IIR/CR rubber blend organoclay nanocomposites. Rubber Chem. Technol. 87, 10-20 (2014)

5. Krishnan, S., Alex, R., Kurian, T.: HAF/Silica/Nanoclay "Ternary" Masterbatch and $\mathrm{HAF} /$ silica binary masterbatch from fresh natural rubber latex. Rubber Chem. Technol. 87, 250-263 (2014)

6. Rooj, S., Das, A., Heinrich, G.: Tube-like natural halloysite/fluoroelastomer nanocomposites with simultaneous enhanced mechanical, dynamic mechanical and thermal properties. Eur. Polym. J. 47, 1746-1755 (2011)

7. Sui, G., Zhong, W.H., Yang, X.P., Yu, Y.H., Zhao, S.H.: Preparation and properties of natural rubber composites reinforced with pretreated carbon nanotubes. Polym. Adv. Technol. 19, 1543-1549 (2008)

8. Deng, C.M., Chen, M., Ao, N.J., Yan, D., Zheng, Z.Q.: $\mathrm{CaCO}_{3}$ /natural rubber latex nanometer composite and its properties. J. Appl. Polym. Sci. 101, 3442-3447 (2006)

9. Mishra, S., Shimpi, N.G.: Mechanical and flame-retarding properties of styrene-butadiene rubber filled with nano- $\mathrm{CaCO}_{3}$ as a filler and linseed oil as an extender. J. Appl. Polym. Sci. 98, 2563-2571 (2005)

10. Mishra, S., Shimpi, N.G., Patil, U.D.: Effect of nano $\mathrm{CaCO}_{3}$ on thermal properties of styrene butadiene rubber (SBR). J. Polym. Res. 14, 449-459 (2007)

11. Mishra, S., Shimpi, N.G.: Studies on mechanical, thermal, and flame retarding Properties of Polybutadiene Rubber (PBR) Nanocomposites. Polym. Plast. Technol. Eng. 47, 72-81 (2007)

12. Mishra, S., Shimpi, N.G., Mali, A.D.: Influence of stearic acid treated nano- $\mathrm{CaCO}_{3}$ on the properties of silicone nanocomposites. J. Polym. Res. 18, 1715-1724 (2011)

13. Ghari, H.S., Arani, A.J., Shakouri, Z.: Mixing sequence in natural rubber containing organoclay and nano-calcium carbonate ternary hybrid nanocomposites. Rubber Chem. Technol. 86, 330-341 (2013)

14. Ghari, H.S., Shakouri, Z.: Natural rubber hybrid nanocomposites reinforced with swelled organoclay and nano-calcium carbonate. Rubber Chem. Technol. 85, 132-146 (2012) 
15. Rana, D., Mandal, B.M., Bhattacharyya, S.N.: Analogue calorimetric studies of blends of poly(vinyl ester)s and polyacrylates. Macromolecules 29, 1579-1583 (1996)

16. Rana, D., Mandal, B.M., Bhattacharyya, S.N.: Analogue calorimetry of polymer blends: poly(styrene-co-acrylonitrile) and poly(phenyl acrylate) or poly(vinyl benzoate). Polymer 37, 2439-2443 (1996)

17. Rana, D., Mandal, B.M., Bhattacharyya, S.N.: Miscibility and phase diagrams of poly(phenyl acrylate) and poly(styrene-coacrylonitrile) blends. Polymer 34, 1454-1459 (1993)

18. Das, A., Costa, F.R., Wagenknecht, U., Heinrich, G.: Nanocomposites based on chloroprene rubber: effect of chemical nature and organic modification of nanoclay on the vulcanizate properties. Eur. Polym. J. 44, 3456-3465 (2008)

19. Subramaniam, K., Das, A., Steinhauser, D., Klüppel, M., Heinrich, G.: Effect of ionic liquid on dielectric, mechanical and dynamic mechanical properties of multi-walled carbon nanotubes/polychloroprene rubber composites. Eur. Polym. J. 47, 2234-2243 (2011)

20. Das, A., Mahaling, R.N., Stöckelhuber, K.W., Heinrich, G.: Reinforcement and migration of nanoclay in polychloroprene/ ethylene-propylene-diene-monomer rubber blends. Comp. Sci. Technol. 71, 276-281 (2011)

21. Subramaniam, K., Das, A., Häußler, L., Harnisch, C., Stöckelhuber, K.W., Heinrich, G.: Enhanced thermal stability of polychloroprene rubber composites with ionic liquid modified MWCNTs. Polym. Degrad. Stab. 97, 776-785 (2012)

22. Dubey, K.A., Bhardwaj, Y.K., Rajkumar, K., Panicker, L., Chaudhari, C.V., Chakraborty, S.K., Sabharwal, S.: Polychloroprene rubber/ethylene-propylene diene monomer/multiple walled carbon nanotube nanocomposites: synergistic effects of radiation crosslinking and MWNT addition. J. Polym. Res. 19, 9876 (2012)

23. Fahma, F., Hori, N., Iwata, T., Takemura, A.: Preparation and characterization of polychloroprene nanocomposites with cellulose nanofibers from oil palm empty fruit bunches as a nanofiller. J. Appl. Polym. Sci. 131, 40159 (2014)

24. Choi, S.S.: Improvement of properties of silica-filled natural rubber compounds using Polychloroprene. J. Appl. Polym. Sci. 83, 2609-2616 (2002)

25. Sae-oui, P., Sirisinha, C., Thepsuwan, U., Hatthapanit, K.: Dependence of mechanical and aging properties of chloroprene rubber on silica and ethylene thiourea loadings. Eur. Polym. J. 43, 185-193 (2007)

26. Ismail, H., Ramly, A.F., Othman, N.: Effects of silica/multiwall carbon nanotube hybrid fillers on the properties of natural rubber nanocomposites. J. Appl. Polym. Sci. 128, 2433-2438 (2013)

27. Gamelas, J.A.F., Lourenco, A.F., Ferreira, P.J.: New modified filler obtained by silica formed by sol-gel method on calcium carbonate. J. Sol-Gel. Sci. Technol. 59, 25-31 (2011)

28. Nekhamanurak, B., Patanathabutr, P., Hongsriphan, N.: Mechanical properties of hydrophilicity modified $\mathrm{CaCO}_{3}$-Poly (Lactic Acid) Nanocomposite. Int. J. Appl. Phys. Math. 2, 98-103 (2012)

29. Yan, S., Yin, J., Yang, J., Chen, X.: Structural characteristics and thermal properties of plasticized poly(l-lactide)-silica nanocomposites synthesized by sol-gel method. Mater. Lett. 61, 2683-2686 (2006)

30. Ramesan, M.T., Mathew, G., Kuriakose, B., Alex, R.: Role of dichlorocarbene modified styrene butadiene rubber in compatibilisation of styrene butadiene rubber and chloroprene rubber blends. Eur. Polym. J. 37, 719-728 (2001)

31. Balachandran, M., Bhagawan, S.S.: Mechanical, thermal, and transport properties of nitrile rubber-nanocalcium carbonate composites. J. Appl. Polym. Sci. 126, 1983-1992 (2012)

32. Usuki, A., Kawasumi, M., Kojima, Y., Okada, A., Kurauchi, T., Kamigaito, O.: Synthesis of nylon 6-clay hybrid. J. Mater. Res. 8, 1179-1184 (1993)

33. Flory, P.J., Renher, J.J.: Statistical mechanics of cross-linked polymer networks II. Swelling. J. Chem. Phys. 11, 521-526 (1943)

34. Chokanandsombat, Y., Sirisinha, C.: $\mathrm{MgO}$ and $\mathrm{ZnO}$ as reinforcing fillers in cured polychloroprene rubber. J. Appl. Polym. Sci. 128, 2533-2540 (2013)

35. Panampilly, B., Thomas, S.: Nano $\mathrm{ZnO}$ as cure activator and reinforcing filler in natural rubber. Polym. Eng. Sci. 53, 1337-1346 (2013)

36. Roy, K., Alam, M.N., Mandal, S.K., Debnath, S.C.: Sol-gel derived nano zinc oxide for the reduction of zinc oxide level in natural rubber compounds. J. Sol-Gel. Sci. Technol. 70, 378-384 (2014) 